A 72-year-old woman with known liver metastases was admitted to our Institute with an acute malignant colorectal obstruction. Colonoscopy revealed a serrated neoplastic stenosis at the splenic flexure and left-sided diverticular disease, with a narrowed, fixed and acute-angled sigmoid colon. An uncovered Wallstent Enteral endoprosthesis (Boston Scientific, Galway, Ireland) was successfully placed (Figure 1), which led to immediate relief of the patient's obstructive symptoms. A radiological control was performed 24 hours later which confirmed satisfactory stent placement.

One month after stent placement and after five cycles of chemotherapy, the patient was readmitted with abdominal pain and constipation. A plain abdominal radiograph showed that the stent had migrated into the sigmoid colon and that there was free gas in the peritoneal cavity. An emergency laparotomy was performed: there were signs of peritonitis and the wire tips of the stent were found to have perforated the wall of the sigmoid colon (Figure 2). The patient underwent left hemicolectomy and a colostomy was performed. Pathological examination revealed a perforation in the sigmoid colon at the site of stent migration, without any neoplastic infiltration. The patient is still alive 7 months after the perforation.

Stent migration, bowel perforation, and obstruction of the stent are the most frequent complications observed after stent placement. Stent migration is reported in about $12 \%$ of cases and usually occurs early after insertion [1]. Colonic perforation that is not related to the stent placement procedure itself is a rare complication (less than $4 \%$ ), and is usually caused by erosion of the colonic wall by the wire ends of the stent at the tumor site [2-5].

\title{
Delayed colonic perforation after metal stent placement for malignant colorectal obstruction
}

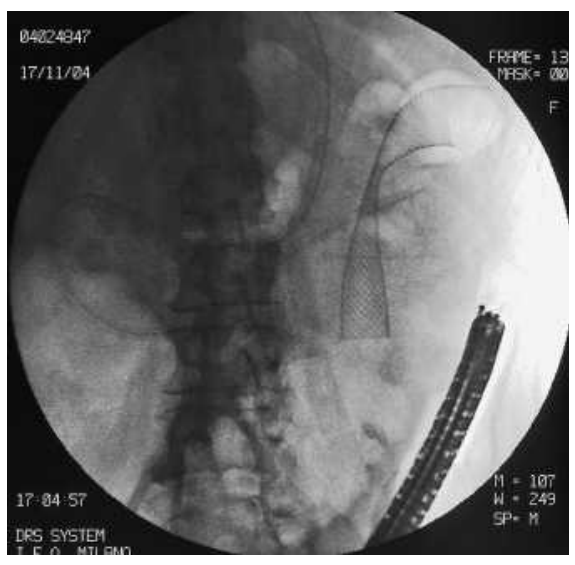

Figure 1 Radiograph showing the stent successfully placed in a stricture at the splenic flexure.

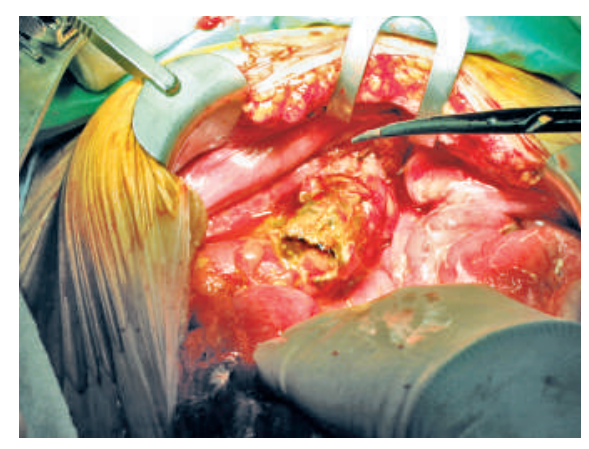

Figure 2 At emergency laparotomy the wire tips of the stent were found to be perforating the wall of the sigmoid colon.

In our patient, perforation occurred 1 month after stent insertion as a consequence of trauma from the stent, which had migrated to a tortuous sigmoid colon with diverticula. We suggest that patients in whom a stent is placed proximal to a tortuous sigmoid colon with diverticula should be evaluated and followed up very carefully.

Endoscopy_UCTN_Code_CPL_1AJ_2AF

\author{
C. Trovato', G. Fiori'ㄹ, D. Ravizza1, \\ D. Tamayo', M. G. Zampino ${ }^{2}$, R. Biffi ${ }^{3}$, \\ C. Crosta ${ }^{1}$ \\ ${ }^{1}$ Division of Endoscopy, European Insti- \\ tute of Oncology, Milan, Italy \\ 2 Department of Medical Oncology, Euro- \\ pean Institute of Oncology, Milan, Italy \\ ${ }^{3}$ Emergency Surgical Oncologogy, Euro- \\ pean Institute of Oncology, Milan, Italy.
}

\section{References}

${ }^{1}$ Sebastian S, Johnston S, Geoghegan T et al. Pooled analysis of the efficacy and safety of self-expanding metal stenting in malignant colorectal obstruction. Am J Gastroenterol 2004; 99: 2051 - 2057

${ }^{2}$ Camúñez F, Echenagusia A, Simó G et al. Malignant colorectal obstruction treated by means of self-expanding metallic stents: effectiveness before surgery and in palliation. Radiology 2000; 216: $492-497$

${ }^{3}$ Han YM, Lee JM, Lee TH. Delayed colon perforation after palliative treatment for rectal carcinoma with bare rectal stent: a case report. Korean J Radiol 2000; 1: 169- 171

${ }^{4}$ Low DE, Panto PN, Hastings AG et al. An unusual complication of a colonic wallstent. Cardiovasc Intervent Radiol 2004; 27: 377-378

${ }^{5}$ Mainar A, De Gregorio Ariza MA, Tejero E et al. Acute colorectal obstruction: treatment with self-expandable metallic stents before scheduled surgery: results of a multicenter study. Radiology 1999; 210: 65-69

\section{Corresponding Author}

\section{Trovato, M.D.}

European Institute of Oncology

Division of Endoscopy

Via Ripamonti 435

20141 Milan

Italy

Fax: +39-02-57489353

E-mail: cristina.trovato@ieo.it 